\title{
O olhar enunciativo da semântica argumentativa sobre a carta de Vargas
}

\author{
Leci Borges Barbisan ${ }^{1}$ \\ Telisa Furlanetto Graeff ${ }^{2}$
}

\begin{abstract}
Résumé: Cet article veut analyser les sens argumentatifs de la LETTRE TESTAMENT DE VARGAS à partir de la théorie de L`argumentation dans la Langue (ADL) créée par Jean-Claude Anscombre et Oswald Ducrot, plus spécialement à partir de sa version actuelle, la Théorie des Blocs Sémantiques (TBS), présentée par Marion Carel et développée avec Oswald Ducrot. L'ADL/TBS se propose de considérer comme rapports sémantiquement pertinents entre les signes, les relations syntagmatiques, c'està-dire, les enchaînements argumentatifs dits normatifs ayant un connecteur du type de donc ou bien les enchaînements dits transgressifs, du type de pourtant. Les enchaînements comme ceux-là, authorisés par un signe, sont ceux qui constituent leurs sens. Comme l'argumentation interne du titre Lettre-testament exige qu' on réponde aux questions: Qui est-ce le donnateur de l'héritage? Quel est son légué? Qui sont-ils, les bénéficiés? On a cherché aussi les fondements de la Théorie de 1'Argumentation Polyphonique (TAP) proposée par Ducrot et Carel, qui réunit les principes de la conception argumentative du sens et de la Théorie de la Polyphonie de Ducrot. L'ADL/TBS et la TAP ont permis d'expliciter l'image que la Lettre Testament présente du donnateur de l'héritage, des bénéficiés, des oppositeurs et du légué. La relation entre les argumentations et les Personnes qui les garantissent, a conduit à des réponses, en révélant le sens du discours et de son titre.
\end{abstract}

Mots-Clés: Argumentation. Lettre de Vargas. Enchaînement argumentatif. Polyphonie. Sens.

Resumo: $\mathrm{O}$ artigo pretende mostrar os sentidos argumentativos da Carta Testamento de Vargas, com base na teoria da Argumentação na Língua (ADL), de Ducrot e Anscombre, mais especificamente, na sua versão atual, a Teoria dos Blocos Semânticos (TBS), apresentada por Carel e desenvolvida juntamente com Ducrot. A ADL/TBS propôs considerar como relações semanticamente pertinentes entre um signo e outro as relações sintagmáticas, ou seja, os encadeamentos argumentativos com conector do tipo de portanto, ditos normativos, ou do tipo de mesmo assim, ditos transgressivos. Encadeamentos como esses, autorizados por um signo, são os que constituem seu sentido. Como a argumentação interna do título Carta Testamento requer que se responda às perguntas: quem é o doador da

1 Docente do Programa de Pós-Graduação em Letras da Pontifícia Universidade Católica do Rio Grande do Sul. barbisan@pucrs.br

2 Docente do Programa de Pós-Graduação em Letras da Universidade de Passo Fundo /RS telisagraeff@ yahoo.com.br 
herança? qual é o legado? quem são os beneficiados?, buscou-se, também, a fundamentação na Teoria da Argumentação Polifônica (TAP), proposta por Ducrot e Carel, que reúne princípios da concepção argumentativa de sentido e da Teoria da Polifonia de Ducrot. A ADL/TBS e a TAP permitiram explicitar a imagem que a Carta Testamento apresenta do doador da herança, dos beneficiados, dos opositores e do legado. A relação entre as argumentações e as Pessoas que os garantem, conduziu às respostas, revelando o sentido do discurso e do título.

Palavras-chave: Argumentação. Carta Testamento. Encadeamento argumentativo. Polifonia. Sentido.

\section{Introdução}

Este artigo tem o objetivo do mostrar os sentidos argumentativos da Carta Testamento de Vargas, com base na teoria da Argumentação na Língua (ADL), proposta por Ducrot e Anscombre, mais especificamente, na sua versão técnica atual, a Teoria dos Blocos Semânticos (TBS), apresentada por Carel e desenvolvida juntamente com Ducrot. Pode-se afirmar que a ADL/TBS é uma aplicação do estruturalismo saussuriano à semântica linguística, na medida em que, para Saussure, o significado de uma expressão reside em suas relações com outras expressões da língua. Considerando que a expressão "relação de um signo com outros" é relativamente vaga, a ADL/TBS propôs considerar como relações semanticamente pertinentes entre um signo e outro as relações sintagmáticas/ argumentativas, ou seja, os encadeamentos argumentativos com conector do tipo de portanto, ditos normativos, ou do tipo de mesmo assim, ditos transgressivos. Em consequência, os encadeamentos em portanto e/ou em mesmo assim, autorizados por um signo, são os que constituem seu sentido. Nesses dois tipos de encadeamentos, manifesta-se o fenômeno chamado de interdependência semântica, ou seja, que cada um dos dois segmentos encadeados toma somente seu sentido na relação com o outro. Conforme a ADL/TBS, como se lê na Conferencia 3, de Ducrot (2005), a significação de uma entidade linguística, isto é, sua argumentação interna (AI) e sua argumentação externa (AE), é constituída somente por aspectos argumentativos, sendo, por isso, inconfrontável com os objetos que percebemos. Um aspecto argumentativo pertence à AI de uma entidade se, isolado, ele é o único de seu bloco semântico a pertencer à significação dessa entidade, pertencendo à sua $\mathrm{AE}$ se seu converso ou seu transposto igualmente pertencerem à significação dessa entidade.

Como a argumentação interna do título Carta Testamento requer que se responda às perguntas: quem é o doador da herança? qual é o legado? quem são os beneficiados?, buscou-se, também, a fundamentação da Teoria da Argumentação Polifônica (TAP), proposta por Ducrot e Carel, que reúne princípios da concepção argumentativa de sentido e da Teoria da Polifonia de Ducrot, criando uma matriz de sentido, constituída por um tripé que contém os seguintes elementos da significação: uma atitude do locutor diante do enunciado; um conteúdo argumentativo (representado por encadeamentos em DC ou em PT) e uma Pessoa, instância que, como as outras duas não é do tipo referencial, não podendo, portanto, ser vista como uma alusão a indivíduos, a qual apresenta, refuta ou garante o dito.

A ADL/TBS e a TAP permitiram mostrar os sentidos argumentativos da Carta Testamento e das Pessoas que os garantem, pelo estabelecimento dessas matrizes de sentido, 
pelo que se pôde, então, explicitar a imagem que a Carta Testamento apresenta do doador da herança, dos beneficiados, dos opositores e do legado. A relação entre as argumentações e as Pessoas que os garantem, conduziu às respostas, revelando o sentido do discurso e do título.

Na sequência do capítulo, será apresentada a fundamentação teórica, a análise da Carta $\mathrm{e}$, então, as respostas às questões que norteiam este trabalho.

\section{Base teórica}

Para se chegar a identificar a imagem que a Carta-Testamento apresenta de seu locutor $(e u)$ de seu alocutário $(t u)$ e do ele, toma-se uma Semântica linguística: a Teoria dos Blocos Semânticos, que se inscreve na Teoria da Argumentação na Língua.

Filiando-se a Ferdinand de Saussure, a Teoria da Argumentação na Língua encontra nas noções saussurianas de signo, língua, fala, relação e valor linguístico, os fundamentos de sua teoria semântica. É nos signos, constituídos de significante e significado, na língua, entidade abstrata criada pelo linguista, e no enunciado, que Ducrot vai buscar explicação para a noção de valor argumentativo. Entende ele que a significação do signo orienta, por semelhança e por diferença, para a significação de outros signos que comporão suas continuações possíveis, resultando, por relação semântica, um encadeamento em que a união das significações dos dois signos, por meio dos conectores portanto e mesmo assim, constrói o sentido do enunciado, chegando, desse modo, ao nível da fala e do discurso. É pela relação de interdependência semântica entre signos que o sentido se constrói no discurso.

Essa é a explicação fundamental que Ducrot propõe para a compreensão de como o sentido é construído pelo locutor, que emprega a língua para produzir discurso. Seu procedimento metodológico - como se pode ler no capítulo 11 da terceira edição de seu livro Dire et ne pas dire (2008) - parte da compreensão dos sentidos produzidos no discurso para buscar, na língua, a explicação de como esta se organiza para produzir aqueles sentidos. Assim, a Teoria da Argumentação na Língua torna-se uma teoria essencialmente linguística, ao considerar que a argumentação está na própria língua.

A Teoria dos Blocos Semânticos, que aprofunda e radicaliza a Teoria da Argumentação na Língua, parte da mesma tese de que a relação estabelecida pelos conectores do tipo de DONC (portanto) e do tipo de POURTANT (mesmo assim) une dois predicados semanticamente interdependentes. Segundo a tese que sustenta a Teoria da Argumentação na Língua e a Teoria dos Blocos Semânticos, é por paráfrases argumentativas que o conteúdo do enunciado é explicado, porque as frases da língua têm natureza semântica: as argumentações comunicadas pelos discursos já estão presentes na significação das palavras, que orientam para as continuações que vão constituir o sentido dos enunciados, explica Carel (2012). Em vista da natureza essencialmente linguística da construção de sentidos pela relação entre signos, os conteúdos dos enunciados assim constituídos, não representam o mundo, não substituem coisas verdadeiras ou falsas, não são produzidos pela adição de traços semânticos, nem são o resultado de uma reunião racional de informações. Diferentemente de outras abordagens da linguagem, explica Carel (2012, p. 32): Falar consiste em relacionar palavras que se referem a esquemas argumentativos, em entrelaçá-los. Nossos discursos são entrelaçamentos de palavras "reunidos em certa ordem".

Tomem-se, como exemplo, os segmentos $\mathrm{A}$ e $\mathrm{B}$, em que $\mathrm{A}=$ ser rico e $\mathrm{B}=$ ser feliz. É possível, nessa relação semântica, a construção de quatro aspectos de um mesmo bloco semântico. São eles: 
A DC B: ser rico DC ser feliz

A PT neg-B: ser rico PT neg-ser feliz

neg-A PT B: neg-ser rico PT ser feliz

neg-A DC neg-B: neg-ser rico DC neg-ser feliz

Há a possibilidade de outros quatro encadeamentos:

A DC neg-B: ser rico DC neg-ser feliz

A PT B: ser rico PT ser feliz

Neg-A DC B: neg-ser rico DC ser feliz

Neg-A PT Neg-B: neg-ser rico PT neg-ser feliz

Percebe-se, então, que há possibilidade de construção de oito encadeamentos a partir de A e B e que a interdependência semântica entre A e B é a mesma nos oito aspectos dos blocos. Reafirma-se, então, que o sentido é construído por um conjunto de relações entre palavras da língua. O sentido de uma palavra depende da continuação que lhe é dada. As relações argumentativas formais, apresentadas pelo jogo de conectores e da negação, representam relações discursivas, que descrevem, consequentemente, a língua pela língua. Não se trata de inferências, nem de raciocínios lógicos, nem de deduções. Os sentidos se constroem pelas relações semânticas entre palavras da língua, não pela exterioridade. Essa é a proposta da ADL/TBS.

A significação de uma entidade linguística fora do emprego é constituída por um certo número, variável segundo a entidade, de aspectos normativos ou transgressivos. Prefigura, assim, a significação de frases em que a entidade aparece : ela dá os esquemas de encadeamentos que parafrasearão essas frases.

Conforme a TBS (CAREL, 2012, p.7-58), a significação de uma entidade linguística é constituída somente por aspectos argumentativos, sendo, assim, inconfrontável com os objetos que se possam perceber ou medir. Vejam-se os sentidos produzidos no bloco semântico da avareza, por exemplo.

BLOCO DA AVAREZA

\begin{tabular}{|c|c|}
\hline avaro & gastador \\
ÚTIL PT NEG COMPRA & NEG ÚTIL PT COMPRA \\
\hline $\begin{array}{c}\text { NEG ÚTIL DC NEG COMPRA } \\
\text { econômico }\end{array}$ & ÚTIL DC COMPRA \\
não avaro \\
\hline
\end{tabular}

A significação linguística de uma palavra é formada por duas partes, uma que se chama argumentação interna e que é constituída por aspectos isolados, outra que se chama argumentação externa e que é constituída por possibilidades alternativas.

Um aspecto argumentativo pertence à AI de uma palavra se, isolado, ele é o único de seu bloco semântico a pertencer à significação da palavra. PERIGO DC NEG FAz pertence à $\mathrm{AI}$ de prudente, DIFÍCIL PT COMPREENDE pertence à AI de inteligente.

Um aspecto pertence à AE de uma palavra se seu converso ou seu transposto pertencem igualmente à significação da palavra. A alternativa dos dois conversos QUALIDADE DC APRECIA e QUALIDADE PT NEG APRECIA pertence à AE de indulgente; a alternativa dos dois transpostos RESPONSÁVEL DC PRUDENTE e NEG RESPONSÁVEL PT PRUDENTE pertence à AE de prudente. 
A Teoria dos Blocos Semânticos (TBS) e a Teoria Argumentativa da Polifonia (TAP) são complementares. A TBS trata dos conteúdos, e a TAP, da colocação dos conteúdos no discurso. A TAP, desenvolvida principalmente por Marion Carel no CRAL (Centre de Recherches sur les Arts et le Langage) da École des Hautes Études en Sciences Sociales de Paris, tem como objeto de estudo a enunciação própria ao enunciado. Segundo algumas teorias, relata Carel em seu texto de 2012, a enunciação é parte não representacional do sentido, que contém apreciações sobre o valor de verdade atribuído ao mundo. Outras teorias entendem a enunciação como o estado psicológico do locutor ou de outro. A Teoria Argumentativa da Polifonia rejeita a hipótese de que o sentido do enunciado se decompõe em duas partes: a de um elemento que descreve o mundo pelos valores de verdade e a de outro elemento que exprime a apreciação do locutor sobre esses valores. Segundo Carel (2012), é no interior do conteúdo que se encontra a enunciação. A TAP mantém a distinção entre o conteúdo e sua colocação em discurso (mise en discours). A colocação em discurso apresenta duas indicações: a da função textual do conteúdo, e a do modo de aparecimento desse conteúdo no discurso.

A função textual pode ter três formas: a do conteúdo assumido, a do concordado e a do excluído. $\mathrm{O}$ assumido e o concordado não podem ser contrariados na sequência do discurso. São planos de fundo. O conteúdo afirmado é o aceito pelo locutor. Só os conteúdos assumidos são continuados no discurso. O conteúdo acordado é sempre subordinado a um conteúdo assumido. A subordinação pode completar outro conteúdo. O conteúdo subordinado, de segundo plano, forma um todo com outro conteúdo, constituindo, ambos, um motivo enunciativo. A exclusão, terceira função, é negativa e não afirmada na continuação do discurso. Os conteúdos excluídos dependem dos conteúdos assumidos e constituem com eles um único motivo argumentativo.

Quanto ao modo de aparecimento do conteúdo no discurso, a TAP o descreve por meio das Pessoas Enunciativas, que não são indivíduos; são seres míticos em número restrito. Dentre as Pessoas Enunciativas, a TAP distingue o Mundo, o Locutor, o Ausente Ele e a Testemunha, (a Pessoa tu). A Pessoa de Locutor indica um modo de aparecimento: o modo do concebido, o modo investido. Além do modo de aparecimento investido da Pessoa de Locutor, há dois outros: o do encontrado (Pessoa do Mundo) e o do recebido (Pessoa do Ausente Ele). A Pessoa do Mundo apresenta os conteúdos dos enunciados factuais, livres de subjetividade, com locutor desinvestido. Na Pessoa do Ausente encontra-se a expressão $p a-$ rece que, que aponta para um desinvestimento não factual do Locutor. A Pessoa do Ausente é marca de subjetividade, mais incerta, porém, do que a da Pessoa do Mundo.

\section{Procedimentos}

Assumindo a noção de motivo argumentativo (CAREL, 2011), segundo a qual uma parte de texto constitui um motivo argumentativo se, ao mesmo tempo, ela exprime um aspecto argumentativo e evoca um encadeamento argumentativo, isto é, se ela comunica um julgamento argumentativo completo, dividiu-se o texto em trechos que permitissem evocar, pelo menos, um encadeamento argumentativo, ao qual se associou o aspecto argumentativo nele expresso. Em seguida, analisou-se a atitude do locutor diante do julgamento argumentativo (de pôr, excluir e concordar) e também a Pessoa que garantia esse conteúdo argumentativo (EU, TU, ELE, MUNDO, OPINIÃO PÚBLICA, entre outros).

Com base nesses sentidos argumentativos da Carta Testamento, pôde-se, então, explicitar as imagens que a Carta Testamento apresenta do doador da herança (locutor), dos beneficiados, dos opositores e do legado. 
3. Análise argumentativa e polifônica da Carta Testamento3

\section{Trecho 1}

\section{Mais uma vez, as forças que os interesses contra o povo coordenaram nova- mente, se desencadeam sôbre mim.}

Desse trecho é possível evocar o encadeamento argumentativo coordenação de forças contra o povo DC contra mim, ao qual se pode associar o aspecto AGIR CONTRA O POVO DC AGIR CONTRA O SEU REPRESENTANTE, que constitui o sentido de união inalienável entre líder e povo. Note-se que esse sentido é posto pelo locutor e por ele garantido.

\section{Trecho 2}

Não me acusam, me insultam; não me combatem, caluniam e não me dão o direito de defesa.

Desse trecho evocam-se os conceitos de julgamento e de julgamento sumário. Observem-se:

acusar, combater DC ter direito de defesa (julgamento)

insultar, caluniar DC neg ter direito de defesa (julgamento sumário)

O locutor exclui o primeiro conteúdo, atribuído à Pessoa Mundo, pondo o segundo conteúdo, como concebido por ele mesmo. Conforme o Locutor da Carta, ele é vítima de um julgamento sumário [insultar, caluniar DC neg direito de defesa].

\section{Trecho 3}

Precisam sufocar minha voz e empedir a minha ação, para que eu não continue a defender, como sempre defendi, o povo e principalmente os humildes.

O trecho três reitera a ideia de que são um só o povo e o líder, uma vez que o líder não falaria para se defender, mas para defender o povo. O julgamento é feito sem direito de defesa, é um julgamento sumário do líder cujas ações têm como motivação a defesa do povo. Confiram-se os encadeamentos normativos recíprocos, ambos garantidos pelo EU, locutor da Carta.

falar, agir DC poder defender o povo

neg falar, neg agir DC neg poder defender o povo

\section{Trecho 4}

\section{Sigo o destino que me é imposto.}

No trecho 4, são apresentados os sentidos discursivos de destino e de destino imposto: [querer defender o povo DC defender] = destino; [querer defender o povo PT ser impedido] = destino imposto. Note-se que esses dois sentidos estão em relação de oposição, uma vez que o EU afirma não seguir o destino que gostaria de seguir, mas o que é obrigado a seguir; o que equivaleria a uma estrutura com MAS de negação metalinguística como

3 Os trechos mantêm a grafia do original. 
"não sigo o meu destino, MAS o que me impõem seguir". O destino imposto impede o locutor de realizar o seu destino de defender o povo.

Nos trechos 5, 6 e 7 que seguem, o locutor faz uma retrospectiva de sua trajetória iniciada com a conquista da liderança popular, seguida com a luta pelos direitos do povo e seus percalços. Trata-se de uma exemplificação da realização do seu destino de defender o povo e dos obstáculos que o fizeram capitular e dizer "Sigo o destino que me foi imposto."

\section{Trecho 5}

Depois de decenios de domínios e espoliação dos grupos economicos e financeiros internacionais, fiz-me chefe de uma revolução e venci. Iniciei o trabalho de libertação e instaurei um regime de liberdade social. Tive que renunciar.

Desse trecho evocam-se dois encadeamentos: o primeiro, que expressa realização de destino [vencer revolução pelo povo DC iniciar trabalho de libertação do povo] e o segundo, que expressa impedimento de realização do destino [instaurar regime de liberdade social PT ser impedido de continuar].

\section{Trecho 6}

Voltei ao governo nos braços do povo. A campanha subterranea dos grupos internacionais aliou-se a dos grupos nacionais revoltados contra o regimem de garantia do trabalho. A lei de lucros extraordinarios foi detida no Congresso. Contra a justiça da revisão do salario mínimo se desencadearam os ódios. Quis crear a liberdade nacional de potencialização das nossas riquezas atraves da Petrobras, e mal começa esta a funcionar a onda de agitação se avoluma. A Eletrobras foi obstaculada até o desespero. Não querem que o trabalhador seja livre. Não querem que o povo seja independente.

Também no trecho 6, como se destacou antes, segue a exemplificação da tentativa de seguir o destino (com a nomeação de conquistas em favor do povo) e dos obstáculos interpostos para impedir o cumprimento do destino. Confiram-se os encadeamentos a partir dele evocados:

vencer o impedimento DC voltar a agir pela liberdade/independência do povo (regime de garantia do trabalho; lei de lucros extraordinários; revisão do salário mínimo; nacionalização da Petrobras; criação da Eletrobras);

voltar a agir pelo povo PT ser impedido

Em síntese, os trechos 5, 6 e também o trecho 7 que segue, explicitam o destino natural do locutor [vocação de agir pelo povo DC agir pelo povo] e o destino que lhe foi imposto [vocação de agir pelo povo PT ser impedido].

\section{Trecho 7}

Assumi o governo dentro da espiral inflacionária, que destruía os valores de trabalho. Os lucros das empresas estrangeiras alcançavam até $500 \%$ ao ano. Nas declarações de valores do que importávamos existiam fraudes constatadas de mais de cem milhões de dólares por ano. Veio a crise do café, valorizou-se o nosso principal produto. Tentamos defender seu preço e a resposta foi uma violenta pressão sobre a nossa economia a ponto de sermos obrigados a ceder. 
Observe-se que do trecho 7 é possível evocar o encadeamento [agir a favor do povo (contra a inflação; contra o lucro das empresas estrangeiras; contra fraude nas importações; a favor da valorização do café) PT ser impedido], ao qual se associa o aspecto expresso [vocação de agir pelo povo PT ser impedido], que constitui uma argumentação interna de destino imposto. Como se mostrou, esse julgamento argumentativo é posto pelo locutor e também garantido por ele, isto é, pela Pessoa EU.

\section{Trecho 8}

Tenho lutado mes a mes, dia a dia, hora a hora, resistindo a uma agressão constante, incessante, tudo suportando em silencio, tudo esquecendo, renunciando a mim mesmo, para defender o povo que agora se queda desamparado.

No trecho 8, a argumentação modifica-se, visto acrescentar-se a ideia da impossibilidade de resistir ao destino imposto. Note-se que [ser impedido de agir PT tentar agir] é a AI de resistência, que pode expressar o referido trecho, com exceção do seu final, mais precisamente do enunciado “ [...] o povo que agora se queda desamparado". A esse final pode-se associar o aspecto [ser reiteradamente impedido de agir DC neg poder resistir mais]. Essa argumentação expressa a ideia de "povo desamparado", povo que não tem mais quem o defenda, uma vez que "povo amparado" seria aquele cujo líder segue seu destino natural, expresso pelo aspecto [vocação de agir pelo povo DC agir pelo povo].

Do trecho 9 em diante, verifica-se a transformação do modo de realização do destino natural, ao mesmo tempo em que é expressa a rejeição definitiva do destino imposto.

\section{Trecho 9}

Nada mais vos posso dar a não ser meu sangue. Se as aves de rapina querem o sangue de alguém, querem continuar sugando o povo brasileiro, eu ofereço em holocausto a minha vida. Escolho este meio de estar sempre convosco. Quando vos humilharem sentireis minha alma sofrendo a vosso lado. Quando a fome bater a vossa porta, sentireis em vosso peito a energia para a luta por vos e vossos filhos. Quando vos vilipendiarem, sentireis no meu pensamento a força para a reação. Meu sacrifício nos manterá unidos e meu nome será a vossa bandeira de luta.

No trecho 9, percebe-se a opção do locutor, garantida pela Pessoa EU, por uma argumentação externa inesperada de não poder mais resistir. Destaque-se que a argumentação externa esperada seria a expressa pelo encadeamento [não poder mais resistir DC não resistir, desistir, capitular]. No entanto, o discurso cria, pela argumentação externa de não poder mais resistir em interdependência semântica com o predicado sacrificar-se, um outro bloco semântico, cujo sentido transforma o destino natural em destino simbólico, isto é, [não poder mais resistir DC sacrificar-se]. Têm-se, então, as argumentações possíveis interna e externa, respectivamente, de sacrificar-se:

AI de sacrificar-se $=$ [oferecer sua vida DC dar prova de amor]

AE de sacrificar-se = [sacrificar-se DC estar para sempre na defesa do povo]; [sacrificar-se DC continuar a luta como herói].

Essa argumentação externa de sacrificar-se será explicitada no trecho 10.

\section{Trecho 10}

Cada gota de meu sangue será uma chama imortal na vossa consciência e manterá a vibração sagrada para a resistência. Ao ódio respondo com o perdão. E aos que 
pensam que me derrotaram respondo com a minha vitória. Era escravo do povo e hoje me liberto para a vida eterna. Mas esse povo de quem fui escravo, não mais será escravo de ninguém. Meu sacrifício ficará para sempre em sua alma e meu sangue será o preço do seu resgate.

Esse trecho trata também da não aceitação do destino imposto e da opção por um novo modo de cumprir o destino, de agir em favor do povo. Vejam-se as argumentações externas de sacrificar-se:

AE de sacrificar-se sacrificar-se DC eternizar a resistência sacrificar-se DC vencer

Como se lê, a morte não é derrota, mas vitória. Confiram-se os encadeamentos evocados do trecho em foco:

estar vivo DC ser derrotado; estar vivo DC estar impossibilitado de resistir ao impedimento de falar e agir

estar morto DC ser vitorioso; estar morto DC ter possibilidade de resistir pela memória das palavras e ações

Percebem-se, também, duas argumentações internas da palavra escravo no enunciado “Mas esse povo de quem fui escravo, não mais será escravo de ninguém." A primeira ocorrência de escravo tem como argumentação interna o encadeamento [amar muito DC dedicar-se inteiramente], já a segunda pode ser parafraseada pelo encadeamento [ser submisso DC não ter autonomia]. O objetivo de livrar o povo da escravidão, nesse segundo sentido, conduz à argumentação externa de sacrificar-se [sacrificar-se DC dar a vida pela libertação do povo], posta pelo locutor e por ele mesmo garantida.

No trecho 11, o locutor retoma argumentações já expressas no discurso e garantidas pela PESSOA EU, quando faz um retrospecto de seu destino natural, do destino imposto e do destino simbólico.

\section{Trecho 11}

Lutei contra a espoliação do Brasil. Lutei contra a espoliação do povo. Tenho lutado de peito aberto. $O$ ódio, as infâmias, a calunia, não abateram meu animo. Vos dei a minha vida. Agora ofereço a minha morte. Nada receio. Serenamente dou o primeiro passo no caminho da eternidade e saio da vida para entrar na Historia.

Note-se que se, no passado, a resistência, para realizar o destino de agir em benefício do povo, era feita com palavras e ações, agora ela passa a ser feita pela memória dessas palavras e ações. Confiram-se os encadeamentos que constituem argumentações externas de resistência pela memória das palavras e ações:

resistência pela memória das palavras e ações DC não poder mais ser impedido; garantir a continuidade da luta

Nessa direção, têm-se o sentido argumentativo de "[...] saio da vida para entrar na História.", em que sair da vida pode ser continuado por DC sair da luta com palavras e ações, e em que entrar na História pode ser continuado por DC continuar a luta simbolicamente, pela memória das palavras e ações.

Em síntese, a Carta Testamento de Vargas trata da rejeição do destino imposto e da transformação do destino natural em destino simbólico, na ótica do locutor que dá a si mesmo como garantia dos julgamentos argumentativos, o que confere ao seu discurso o tom emocionado de quem está engajado e fala de si próprio. 


\section{Conexão Letras}

\section{Considerações finais}

Mostrados os sentidos argumentativos e polifônicos da Carta Testamento, especialmente os vinculados à Pessoa do Locutor, do TU e do ELE, por meio da consideração das relações sintagmáticas/ argumentativas, visto que para a TBS o sentido de uma entidade linguística é constituído pelos encadeamentos argumentativos que essa entidade linguística evoca, de modo interno ou externo, é possível responder à questão norteadora deste capítulo, a de que imagens a Carta apresenta do Locutor, do Tu e do Ele.

Foram encontradas as seguintes imagens do EU:

Imagem 1 = líder cujo destino é libertar um povo oprimido (destino natural);

Imagem 2 = líder impedido de exercer seu destino de libertar o povo oprimido (destino imposto);

Imagem 3 = herói que cumpre seu destino de conduzir o povo à libertação (destino simbólico).

Foram encontradas as seguintes imagens do TU:

Imagem 1 = povo oprimido, totalmente dependente da proteção do líder (... agora se queda desamparado);

Imagem 2 = povo forte, impulsionado pela memória do líder para conquistar sua liberdade (Escolho este meio de estar sempre convosco.) (Mas esse povo ... não será mais escravo de ninguém).

Foram encontradas as seguintes imagens do ELE ou opositores:

Imagem 1 = aqueles que escravizam o povo brasileiro;

Imagem 2 = aqueles que impedem a ação libertadora do líder.

Foram encontradas as seguintes imagens do ELE ou legado:

Imagem 1 = exemplo da resistência na luta pela libertação do povo brasileiro;

Imagem 2 = exemplo da luta com palavras e ações;

Imagem 3 = transformação da arma da luta de palavras e ações (arma impedida) à arma da memória (arma impossível de ser impedida).

Essas imagens linguisticamente constituídas no texto, mais especificamente gestadas no cotexto, constituem pistas seguras para uma pesquisa contextual mais ampla que atenda aos interesses dos que se dedicam ao estudo da era Vargas no Brasil.

\section{Referências}

BOURMAYAN, Anouch, CÁMPORA, Magdalena, CAREL, Marion, COMPAGNO, Dario, LESCANO, Alfredo, SALSMAN, Margot, sous la direction de Marion CAREL. Argumentaciín y Polifonia. Paris: L'Harmattan, 2012.

DUCROT, Oswald. Primera conferencia. In DUCROT, Polifonia y argumentación. Cali: Universidad del Valle, 1990.

DUCROT, Oswald. Argumentación interna y argumentación externa - conferencia 3.

In CAREL, Marion, DUCROT, Oswald. La Semántica Argumentativa. Buenos Aires: Colihue, 2005.

DUCROT, Oswald. Dire et ne pas dire : principes de sématique linguistique. Paris:

Hermann, 2008. 